\title{
Susceptibility to Fluconazole and Ketoconazole of Candida spp. Isolated from Primary and Episodic Vulvovaginites by E-Test (São Paulo, SP, Brazil)
}

\author{
Humberto Fabio Boatto1, Manoel João Batista Castello Girão1, Elaine Cristina Francisco², \\ Alexandre Paulo Machado3*, Maria Sayonara de Moraes4, Olga Fischman² \\ ${ }^{1}$ Department of Gynecology, Faculty of Medicine, Federal University of São Paulo-UNIFESP, São Paulo, Brazil \\ ${ }^{2}$ Department of Microbiology, Immunology and Parasitology, Federal University of São Paulo-UNIFESP, São Paulo, Brazil \\ ${ }^{3}$ Department of Basic Sciences in Health, Faculty of Medicine, Federal University of Mato Grosso-UFMT, São Paulo, Brazil \\ ${ }^{4}$ Dermatologist of São Paulo State Secretary of Health, São Paulo, Brazil \\ Email: ^alepaulo@hotmail.com
}

How to cite this paper: Boatto, H.F., Girão, M.J.B.C., Francisco, E.C., Machado, A.P., de Moraes, M.S. and Fischman, O. (2016) Susceptibility to Fluconazole and Ketoconazole of Candida spp. Isolated from Primary and Episodic Vulvovaginites by E-Test (São Paulo, SP, Brazil). Open Journal of Obstetrics and Gynecology, 6, 689-697. http://dx.doi.org/10.4236/ojog.2016.612086

Received: August 15, 2016

Accepted: November 4, 2016

Published: November 7, 2016

Copyright $\odot 2016$ by authors and Scientific Research Publishing Inc. This work is licensed under the Creative Commons Attribution International License (CC BY 4.0).

http://creativecommons.org/licenses/by/4.0/

\section{(c) (i) Open Access}

\begin{abstract}
Purpose: To evaluate the profile of in vitro susceptibility of yeasts isolated from cases of primary and espisodic vulvovaginitis to two antifungal agents. Methods: 40 Candida isolates from episodes of vulvovaginal candidiasis were identified by classic methodologies. The susceptibility testing of the in vitro fluconazole and ketoconazole activity against the isolates was accessed by E-test. Results: $C$. albicans was the most common species identified in $70 \%$ of the occurrences followed by C. glabrata (20\%), C. tropicalis (7.5\%), and C. guilliermondii (2.5\%). In the susceptibility profile to antifungal agents, $12.5 \%$ and $16.7 \%$ of the isolates obtained from primary and episodic vulvovaginal candidiasis were resistant to fluconazole, respectively. To ketoconazole, we found that $6.25 \%$ and $12.5 \%$ of the isolates respectively from primary vulvovaginal candidiasis (PVVC) and episodic vulvovaginal candidiasis (EVVC) had high MIC values. Conclusions: E-test is a reliable method for the susceptibility testing of Candida spp. due to its simplicity, reproducibility, and lack of specialized equipment. Resistant strains and non-albicans species were verified more in cases of EVVC than in $P V V C$. Clinical and mycological cure of patients with episodic vulvovaginal candidiasis or complicated cases occurred after prolonged treatment and sometimes with multiple antifungals use.
\end{abstract}

\section{Keywords}

Antifungal Susceptibility, Candida, Candidiasis Vulvovaginal, E-Test, Non-Albicans Species 


\section{Introduction}

Vulvovaginal candidiasis (VVC) is classified as primary or non-complicated when manifested by sporadic or infrequent episodes with mild or moderate symptoms in healthy and non-pregnant woman, while complicated episodic and recurrent cases of Candida vulvovaginitis have more severe symptoms and signs with high frequency of resistant yeast species [1] [2]. Changes of $\mathrm{pH}$, vaginal microbiota, and the endogenous host factors may trigger the disease [1]-[4]. Candida albicans has been the most common causal agent and non-albicans species have been increasingly identified [4]-[7]. The overall increase of resistant microorganisms and the consequent occurrence of refractory cases for treatments commonly used have been quicken for the interest in researches to development of new antimicrobial drugs, therapeutic schemes and susceptibility tests [5] [8] [9].

Azole substances have been used as the first-line of antifungal agents for treatment of VVC. However, the susceptibility obtained in vitro is not predictive of therapeutic success [10] [11]. On the other hand, the resistance could be a factor involved in inefficacy of antifungal drug therapy mainly in refractory cases [5] [12] [13].

E-test has been considered as an alternative to the reference broth microdilution method (CLSI) for its practicability and reproducibility [14]-[16]. It is easy, fast, and can be used by the gynecologist for increased reliability of prescription medication, especially in more complicated cases [15]-[17]. Comparison between the E-Test and microdilution showed high reliable correlation to fluconazole, voriconazole and caspofungin [18].

Due to the importance of vulvovaginal candidiasis at gynecological practice and the few Brazilian works on the fungal susceptibility testing of the strains isolated from VVC, the aim of this investigation was to evaluate the in vitro susceptibility to fluconazole and ketoconazole of Candida spp. isolated from primary and episodic cases assessed by E-Test in São Paulo (Brazil).

\section{Material and Methods}

In a prospective study conducted during two years, evaluated in private and public gynecological services in the greater São Paulo city (São Paulo State, Brazil), 562 women between the ages 18 and 65 years were followed up, and 168 of them with clinical suspicion of VVC were carefully investigated. Itching, discharge, erythema, dysuria, vulvar burning, and pain were the signs and symptoms analyzed.

According to the intensity, an arbitrary punctuation was attributed for each manifestation following the score: zero to three-was not considered; four to six-mild; seven to 13 -moderate; 14 to 18 -severe. The criteria of inclusion in this investigation were: patients with age range from 18 to 65 years, with positive cultures for Candida spp., intensity of signs and symptoms equal to greater than four, not pregnant, without any immunocomprising conditions. After the exclusion of women with diabetes mellitus, immuno-deficiency as HIV positive, in use of vaginal douches, spermicides, or intrauterine device (IUD), and on steroid, hormone or antibiotic therapy, 40 patients with 
clinical and laboratory diagnosis of VVC were selected; 16 patients with primary vulvovaginal candidiasis (PVVC) as group A and 24 with episodic vulvovaginal candidiasis (EVVC) as group B. Topical or systemic azole, or the combination of both was used for treatment and the patient evolution was carefully monitored.

The vaginal secretions were collected with non-lubricated speculum from the ectocervix and posterior vaginal fornix, using moistened swab in sterile saline solution. This procedure was performed after science and signing of agreement each patient. The study was approved by the Ethics Committee of the Federal University of São Paulo under $n^{\circ} 1719 / 05$ and conducted according to the Helsinki Declaration revised in 2008.

One part of the samples was submitted to direct microscopy with $\mathrm{KOH} 20 \%$ more ink Parker (three to one) and smears were stained by Gram method. The other part was seeded on Sabouraud dextrose agar media supplemented with chloramphenicol (100 $\mathrm{mg} / \mathrm{ml}$ ) and CHROMagar Candida for screening of presumptive species. The yeast identification was performed according to morphological, biochemical and physiological characterization of the isolated species. Candida albicans identification was confirmed by the presence of chlamidoconidia in cornmeal agar tween 80 , production germ tube at $37^{\circ} \mathrm{C}$ in serum and growth in hypertonic media at $42^{\circ} \mathrm{C}$.

The susceptibility test of the isolates was performed by kit E-Test (AB Biodisk, Solna, Sweden) and the protocol followed the manufacturer's instructions. The assay medium RPMI 1640 agar supplemented with MOPS, L-glutamine, and glucose (HiMedia Laboratories, Bombai, India) was prepared and distributed in $90 \mathrm{~mm}$-diameter Petri-dishes. Candida isolates were previously cultivated for $24 \mathrm{~h}$ on Sabouraud dextrose agar and inoculated on tubes with $3 \mathrm{~mL}$ of sterile saline, turbidity of $0.5 \mathrm{McF}$ arland scale and then seed with sterile swabs on the surface of the medium. After 15 min of drying at room temperature, the E-Test strings of fluconazole and ketoconazole were placed on the agar surface and the plates were incubated at $37^{\circ} \mathrm{C}$. The readings for the minimal inhibitory concentration (MIC) for the antifungal drugs were performed after 24 and $48 \mathrm{~h}$ of incubation. Interpretation of the results for was based on the values of MIC recommended by documents CLSI M27 A2, CLSI M27 A3 and CLSI M27 S4 [19]-[21]. For the ketoconazole there are not established breakpoints. The reference strain Candida parapsilosis ATCC 22019 was included for quality control. All experiments were performed in triplicate.

The Chi-Square tests were used in order to correlate the intensity of clinical forms of PVVC and EVVC and the in vitro susceptibility profile to fluconazole and ketoconazole.

\section{Results}

In this investigation, we analyzed 40 strains of Candida species, 26 from PVVC and 24 from EVVC. Candida albicans (70\%) was the prevalent species, followed by C. glabrata (20\%), C. tropicalis (7.5\%) and C. guilliermondii (1.5\%). The relationship of Candida species isolated from patients with PVVC and EVVC are described in Table 1. Candida glabrata was the prevalent non-albicans species isolated mainly in EVVC.

The intensity of signs and symptoms according to the species of Candida are represented in Table 2. The major number of patients $(72.5 \%)$ presented a moderate degree of 
Table 1. Candida species isolated from 40 cases of primary and episodic VVC.

\begin{tabular}{cccc}
\hline Species & $\begin{array}{c}\text { PVVC } \\
\mathrm{n}(\%)\end{array}$ & $\begin{array}{c}\text { EVVC } \\
\mathrm{n}(\%)\end{array}$ & $\begin{array}{c}\text { Total } \\
\mathrm{n}(\%)\end{array}$ \\
\hline C. albicans & $13(32.25)$ & $15(37.5)$ & $28(70)$ \\
C. glabrata & $1(2.5)$ & $7(17.5)$ & $8(20)$ \\
C. trocipalis & $2(5)$ & $1(2.5)$ & $3(7.5)$ \\
C. guilliermondii & - & $1(2.5)$ & $1(2.5)$ \\
\hline
\end{tabular}

$\mathrm{VVC}=$ vulvovaginal candidiasis, $\mathrm{PVVC}=$ primary VVC, $\mathrm{EVVC}=$ episodic VVC.

Table 2. Signs and symptoms insensitivity of VVC according to identified species.

\begin{tabular}{ccccc}
\hline Species & $\begin{array}{c}\text { Mild } \\
\mathrm{n}(\%)\end{array}$ & $\begin{array}{c}\text { Moderate } \\
\mathrm{n}(\%)\end{array}$ & $\begin{array}{c}\text { Severe } \\
\mathrm{n}(\%)\end{array}$ & $\begin{array}{c}\text { Total } \\
\mathrm{n}(\%)\end{array}$ \\
\hline C. albicans & $8(20)$ & $20(50)$ & - & $28(70)$ \\
C. glabrata & $2(5)$ & $6(15)$ & - & $8(20)$ \\
C. trocipalis & - & $2(5)$ & $1(2.5)$ & $3(7.5)$ \\
C. guilliermondii & - & $1(2.5)$ & - & $1(2.5)$ \\
Total & $10(25)$ & $29(72.5)$ & $1(2.5)$ & $40(100)$ \\
\hline
\end{tabular}

VVC. Mild symptoms and signs were observed in 10 women (25\%) and a severe presentation occurred only in one patient (2.5\%). We do not observed correlation between symptoms and signs, manifestations type (PVVC and EVVC) and identified species. The most common age ranging was verified in patients from 18 to 32 years old.

In PVVC, only two isolates (one C. albicans and one C. glabrata, 12.5\%) of 16 isolates showed resistance to fluconazole (Table 3). In EVVC, five isolates (one C. albicans and 4 C. glabrata) showed high MICs for fluconazole, and 4 isolates were SDD (3 C. glabrata and 1 C. guilliermondii).

In relation to ketoconazole, four isolates of $C$. glabrata (one from PVVC and three from EVVC, respectively 6.25\% and 12.5\%), two C. albicans strains (from PVVC and EVVC), two C. tropicalis strains (from PVVC), and the single-isolate $C$. guilliermondii showed high MICs $>16 \mu \mathrm{g} / \mathrm{ml}$. Five isolates, C. glabrata (4) and C. albicans (1) have proved to be both resistant to fluconazole and high MICs values to ketoconazole. Trailing phenomenon was recorded in $25 \%$ of isolates.

In vitro susceptibility profile of the isolates to antifungal fluconazole and ketoconazole showed no significant clinical correlation with PVVC or EVVC and signs and symptoms in VVC.

In PVVC (group A) there was clinical and mycological cure after the first treatment with fluconazole $150 \mathrm{mg}$ orally once weekly for two weeks. In this group, two samples (12.5\%) were resistant to antifungal, one $C$. albicans isolate (6.25\%) and one C. glabrata isolate (6.25\%). The isolates obtained from the other 14 patients, $C$. albicans (12) and $C$. tropicalis (2) were susceptibility to fluconazole.

In EVVC (group B), 16 patients achieved clinical and mycological cures after the second treatment with fluconazole $150 \mathrm{mg}$ orally once weekly for 3 weeks. In six patients, clinical and mycological cure occurred after the third treatment with ketoconazole orally at $400 \mathrm{mg}$ daily for 14 days. And in the other two patients in this group, healing 
Table 3. In vitro susceptibility profile to fluconazole of Candida species isolated from 40 cases of primary (P) and episodic (E) VVC, assessed by E-Test.

\begin{tabular}{ccccc}
\hline Species & $\mathrm{S}$ & $\mathrm{SDD}$ & $\mathrm{R}$ & Total \\
& $\mathrm{P} / \mathrm{E}$ & $\mathrm{P} / \mathrm{E}$ & $\mathrm{P} / \mathrm{E}$ & 28 \\
C. albicans & $12 / 15$ & $0 / 0$ & $1 / 0$ & 8 \\
C. glabrata & $0 / 0$ & $0 / 3$ & $1 / 4$ & 3 \\
C. trocipalis & $2 / 1$ & $0 / 0$ & $0 / 0$ & 1 \\
C. guilliermondii & $0 / 0$ & $0 / 1$ & $0 / 0$ & 40 \\
Total & $14 / 16$ & $0 / 4$ & $2 / 4$ & 2 \\
\hline
\end{tabular}

$\mathrm{VVC}=$ vulvovaginal candidiasis, $\mathrm{S}=$ susceptible, $\mathrm{SDD}=$ susceptible-dose dependent, $\mathrm{R}=$ resistant.

was given after the fourth treatment with fluconazole $150 \mathrm{mg}$ orally weekly, for 4 weeks up to 6 weeks. We emphasize the occurrence of a higher strength and high MIC observed for $C$. glabrata, including a little therapeutic response especially in EVVC.

\section{Discussion}

Vulvovaginal candidiasis is an insidious infection that affects a large proportion of female patients, most frequently in the reproductive age [1]-[4]. The distinction between bacterial and fungal vaginitis in relation to symptoms and etiological agent contributes to the therapeutic success [22]. Although $C$. albicans is the most frequently isolated species, other species have been found as infectious agents such as C. glabrata, C. tropicalis and C. guillermondii [5] [6] [10] [23]. In our study, C. albicans and C. glabrata were the two most prevalent species. The $C$. glabrata strains were more resistant to antifungal agents commonly used in clinical practice. The resistant species were also frequently involved in relapse after treatment. The relapses were associated with prolongation of time action and consequently higher dosage of the drugs, and sometimes with the use of more than one antifungal during the treatment for VVC.

A recent study using the microdilution methods and disk diffusion resistance recorded Candida spp. emphasizes the need for standardization of methods that allow a better correlation between the resistance patterns and clinical manifestations [24]. Fluconazole resistance in species of $C$. albicans has not been shown as very common [10] [23] [25]-[29] on average less than $10 \%$ of the VVC isolated, while in C. glabatra resistant or susceptible-dose dependent occurring frequently around or more than $50 \%$ of the strains [5] [30]-[34]. In this investigation, $3.5 \%$ and $62.5 \%$ of the isolates of C. albicans and C. glabrata, respectively, proved to be resistant to fluconazole. Most yeast isolates from patients with EVVC, similar to those of the PVVC, in our research, were susceptible to fluconazole and ketoconazole, except $C$. glabrata. A study conducted for 8 years in China, with 2.204 isolates of Candida spp revealed prevalence of $C$. albicans, but an increase of non-albicans species such as $C$. glabrata over the years and antifungal resistance [35]. Unlike our study, in other Chinese research, high rate of resistant isolates for the ketoconazole was detected in 186 Candida strains from patients with VVC [36], observing resistance route $27.7 \%$ in C. albicans strains and $56.2 \%$ in non-albicans 
species.

Cross-resistance between azole antifungals such as fluconazole and ketoconazole is not uncommon fact [28] [32] [36] [37]. In our study, five (12.5\%) isolates were resistant to fluconazole also showed great MICs values to ketoconazole. The selective pressure generated by the previous use of these two antifungal agents in cases of relapse is possibly correlated to the emergence of resistant strains isolated [31] [32] [38]. Fluconazole is inducing agent to selection of $C$. albicans with homozygous profile to $M T L$ gene fast mode and high-frequency [39]. Treatment failure of CVV, in case of relapse or refractory, may also be associated with decreased susceptibility to the antifungal agent [28] [40]. Our investigation found susceptibility dose dependent (SDD) of $C$. guilliermondii to fluconazole and ketoconazole. This isolate was from second episode. This is consistent with other studies that shown C. guilliermondii as an emerging yeast with reduced susceptibility to antifungal agents [6] [23] [24] [41] [42].

Finally, we denote that susceptibility testing to antifungal agents of the isolated yeast of VVC, especially those of clinical significance, is important for detecting resistant microorganisms and may contribute to medical management and consequent therapeutic success, especially in episodic or complicated fungal vulvovaginitis. The intrinsic resistance of many strains and the antifungal drugs used for a long term or inappropriate treatment can leave to resistant-yeast selection among the fungal species [33]. On the other hand, antifungals used for a long period can leave susceptible or susceptible dosedependent microorganisms to become more resistant to multiple drugs [11]. The use of E-test method is interesting as a screening method due to its practicality and a presumptive result of degree of susceptibility. Isolates that showed elevated MIC for the two tested antifungal agents were mainly $C$. glabrata, and much lower percentages of $C$. albicans, the two species most commonly found in this study. Further investigations with more VVC cases are necessary in order to analyze other factors related to the host and to fungal agents that will add to knowledge of the pathogenesis and maintenance of CVV.

\section{Acknowledgements}

We would like to thank CNPq for financial support. To David Wei Ming Wang, Academic Medicine of the School of Medicine, Federal University of São Paulo SP and the General Clinical Medical and Bachelor of Computer Science Dr Reinaldo Leibovici for assistance, reviewing and suggestions during carrying out this work.

\section{References}

[1] White, D.J. and Vanthuyne, A. (2006) Vulvovaginal Candidiasis. Sexually Transmitted Infections, 82, iv28. http://dx.doi.org/10.1136/sti.2006.023168

[2] Hamad, M., Kazandji, N., Awadallah, S. and Allam, H. (2014) Prevalence and Epidemiological Characteristics of Vaginal Candidiasis in the UAE. Mycoses, 57, 184-190. http://dx.doi.org/10.1111/myc.12141

[3] Hong, E., Dixit, S., Fidel, P.L., Bradford, J. and Fischer, G. (2014) Vulvovaginal Candidiasis 
as a Chronic Disease: Diagnostic Criteria and Definition. Journal of Lower Genital Tract Disease, 18, 31-38. http://dx.doi.org/10.1097/LGT.0b013e318287aced

[4] Gunther, L.S., Martins, H.P., Gimenes, F., Abreu, A.L., Consolaro, M.E. and Svidzinski, T.I. (2014) Prevalence of Candida albicans and non-albicans Isolates from Vaginal Secretions: Comparative Evaluation of Colonization, Vaginal Candidiasis and Recurrent Vaginal Candidiasis in Diabetic and non-Diabetic Women. Journal of Medical Microbiology, 63, 14361445. http://dx.doi.org/10.1590/1516-3180.2014.1322640

[5] Richter, S.S., Galask, R.P., Messer, S.A., Hollis, R.J., Diekema, D.J. and Pfaller, M.A. (2005) Antifungal Susceptibilities of Candida Species Causing Vulvovaginitis and Epidemiology of Recurrent Cases. Journal of Clinical Microbiology, 43, 2155-2162. http://dx.doi.org/10.1128/JCM.43.5.2155-2162.2005

[6] Sobel, J. D. (2007) Vulvovaginal Candidosis. The Lancet, 369, 1961-1971. http://dx.doi.org/10.1016/S0140-6736(07)60917-9

[7] Moreira, D., Auler, M.E., Ruiz, L.S., Silva, E.H., Hahn, R.C. and Paula, C.R. (2014) Species Distribution and Antifungal Susceptibility of Yeasts Isolated from Vaginal Mucosa. Revista de Patologia Tropical, 43, 48-56. http://dx.doi.org/10.5216/rpt.v43i1.29371

[8] Sobel, J.D. (2016) Recurrent Vulvovaginal Candidiasis. American Journal of Obstetrics \& Gynecology, 214, 15-21. http://dx.doi.org/10.1016/j.ajog.2015.06.067

[9] Chew, S.Y. and Than, L.T. (2016) Vulvovaginal Candidosis: Contemporary Challenges and the Future of Prophylactic and Therapeutic Approaches. Mycoses, 59, 262-273. http://dx.doi.org/10.1111/myc. 12455

[10] Martins, H.P., da Silva, M.C., Paiva, L.C., Svidzinski, T.I. and Consolaro, M.E. (2012) Efficacy of Fluconazole and Nystatin in the Treatment of Vaginal Candida Species. Acta Dermato-Venereologica, 92, 78-82. http://dx.doi.org/10.2340/00015555-1194

[11] Dias, L.B., de Souza Carvalho Melhem, M., Szeszs, M.W., Filho, J.M. and Hahn, R.C. (2011) Vulvovaginal Candidiasis in Mato Grosso, Brazil: Pregnancy Status, Causative Species and Drugs Tests. Brazilian Journal of Microbiology, 42, 1300-1307. http://dx.doi.org/10.1590/S1517-83822011000400009

[12] Fan, S., Liu, X., Wu, C., Xu, L. and Li, J. (2015) Vaginal Nystatin versus Oral Fluconazole for the Treatment for Recurrent Vulvovaginal Candidiasis. Mycopathologia, 179, 95-101. http://dx.doi.org/10.1007/s11046-014-9827-4

[13] Nguyen, Y., Lee, A. and Fischer, G. (2016) Management of Chronic Vulvovaginal Candidiasis: A Long Term Retrospective Study. Australasian Journal of Dermatology. http://dx.doi.org/10.1111/ajd.12497

[14] Lee, S.C., Lo, H.J., Fung, C.P., Lee, N. and See L.C. (2009) Disk Diffusion Test and E-Test with Enriched Mueller-Hinton Agar for Determining Susceptibility of Candida Species to Voriconazole and Fluconazole. Journal of Microbiology, Immunology and Infection, 42, 148-153.

[15] Campana, E.H., Carvalhaes, C.G., Barbosa, P.P., Machado, A.M.O., Paula, A.M. and Gales, A.C. (2011) Evaluation of M.I.C.E.TM, Etest ${ }^{\circledR}$ and CLSI Broth Microdilution Methods for Antimicrobial Susceptibility Testing of Nosocomial Bacterial Isolates. Jornal Brasileiro de Patologia e Medicina Laboratorial, 47, 157-164. http://dx.doi.org/10.1590/S1676-24442011000200011

[16] Koga-Ito, C.Y., Lyon, J.P. and Resende, M.A. (2008) Comparison between E-Test and CLSI Broth Microdilution Method for Antifungal Susceptibility Testing of Candida albicans Oral Isolates. Revista do Instituto de Medicina Tropical de São Paulo, 50, 7-10. http://dx.doi.org/10.1590/S0036-46652008000100002 
[17] Madhavan, P., Jamal, F., Chong, P.P. and Ng, K.P. (2010) In Vitro Activity of Fluconazole against Clinical Isolates of Candida spp. by E-Test Method. Tropical Biomedicine, 27, 200 207.

[18] Kumar, D., Bhattacharyya, S., Gupta, P., Banerjee, G. and Singh, M. (2015) Comparative Analysis of Disc Diffusion and E-Test with Broth Micro-Dilution for Susceptibility Testing of Clinical Candida Isolates against Amphotericin B, Fluconazole, Voriconazole and Caspofungin. Journal of Clinical and Diagnostic Research, 9, DC01-DC04.

[19] Clinical Laboratory Standards Institute (CLSI) (2002) Reference Method for Broth Dilution Antifungal Susceptibility Testing of Yeasts. Approved Standard Document M27-A2, Wayne, PA.

[20] Clinical Laboratory Standards Institute (CLSI) (2008) Reference Method for Broth Dilution Antifungal Susceptibility Testing of Yeasts. Approved Standard Document M27-S3, Wayne, PA.

[21] Clinical Laboratory Standards Institute (CLSI) (2012) Reference Method for Broth Dilution Antifungal Susceptibility Testing of Yeasts. Approved Standard Document M27-S4, Wayne, PA.

[22] Johnson, S.R., Griffiths, H. and Humberstone, F.J. (2010) Attitudes and Experience of Women to Common Vaginal Infections. Journal of Lower Genital Tract Disease, 14, 287 294. http://dx.doi.org/10.1097/LGT.0b013e3181d85bb7

[23] Barbedo, L.S. and Sgarbi, D.B.G. (2010) Candidiasis. Jornal Brasileiro de Doenças Sexualmente Transmissíveis, 22, 22-38.

[24] Dota, K.F.D., Freitas, A.R., Consolaro, M.E.L. and Svidzinski, T.E.I. (2011) A Challenge For Clinical Laboratories: Detection of Antifungal Resistance in Candida Species Causing Vulvovaginal Candidiasis. Laboratory Medicine, 42, 87-93. http://dx.doi.org/10.1309/LMDFCA8YEZ0MQULA

[25] Cernicka, J. and Subik, J. (2006) Resistance Mechanisms in Fluconazole-Resistant Candida albicans Isolates from Vaginal Candidiasis. International Journal of Antimicrobial Agents, 27, 403-408. http://dx.doi.org/10.1016/j.ijantimicag.2005.12.005

[26] Vijaya, D., Dhanalakshmi, T.A. and Kulkarni, S. (2014) Changing Trends of Vulvovaginal Candidiasis. Journal of Laboratory Physicians, 6, 28-30. http://dx.doi.org/10.4103/0974-2727.129087

[27] Tseng, Y.A., Lee, W.T. and Kuo, T.C. (2005) In-Vitro Susceptibility of Fluconazole and Amphotericin B against Candida Isolates from Women with Vaginal Candidiasis in Taiwan. Journal of Food and Drug Analysis, 13, 12-16.

[28] Shahid, Z. and Sobel, J.D. (2009) Reduced Fluconazole Susceptibility of Candida albicans Isolates in Women with Recurrent Vulvovaginal Candidiasis: Effects of Long-Term Fluconazole Therapy. Diagnostic Microbiology and Infectious Disease, 64, 354-356. http://dx.doi.org/10.1016/j.diagmicrobio.2009.03.021

[29] Feng, L.J., Wan, Z., Wang, X.H., Li, R.Y. and Liu, W. (2010) Relationship between Antifungal Resistance of Fluconazole Resistant Candida albicans and Mutations in ERG11 Gene. Chinese Medical Journal, 123, 544-548.

[30] Burguess, D.S., Hastings, R.W., Summers, K.K., Hardin, T.C. and Rinaldi, M.G. (2000) Pharmacodynamics of Fluconazole, Itraconazole and Amphotericin B against Candida albicans. Diagnostic Microbiology and Infectious Disease, 36, 13-18. http://dx.doi.org/10.1016/S0732-8893(99)00097-8

[31] Deepa, R., Sunil Rao, P. and Kottigade, S. (2014) In-Vitro Susceptibility of Fluconazole Resistant Candidemial Isolates to Mycafungin and Anidulafungin. International Journal of 
Current Microbiology and Applied Sciences, 3, 424-427.

[32] Sanguinetti, M., Posteraro, B. and Lass-Flörl, C. (2015) Antifungal Drug Resistance among Candida Species: Mechanisms and Clinical Impact. Mycoses, 58, 2-13. http://dx.doi.org/10.1111/myc.12330

[33] Badiee, P. and Alborzi, A. (2011) Susceptibility of Clinical Candida Species Isolates to Antifungal Agents by E-Test, Southern Iran: A Five Year Study. Iranian Journal of Microbiology, 3, 183-188.

[34] Silva, M.G.C., Rodrigues, G.S., Gonçalves, I.L. and Grazziotin, N.A. (2015) Distribution of Candida Species and Susceptibility to Fluconazole Isolated from Blood Cultures at the Regional Hospital in Passo Fundo, RS, Brazil. Jornal Brasileiro de Patologia e Medicina Laboratorial, 51, 158-161. http://dx.doi.org/10.5935/1676-2444.20150027

[35] Wang, F.J., Zhang, D., Liu, Z.H., Wu, W.X., Bai, H.H. and Dong, H.Y. (2016) Species Distribution and in Vitro Antifungal Susceptibility of Vulvovaginal Candida Isolates in China. Chinese Medical Journal, 129, 1161-1165. http://dx.doi.org/10.4103/0366-6999.181964

[36] Shi, X.Y., Yang, Y.P., Zhang, Y., Li, W., Wang, J.D., Huang, W.M., et al. (2015) Molecular Identification and Antifungal Susceptibility of 186 Candida Isolates from Vulvovaginal Candidiasis in Southern China. Journal of Medical Microbiology, 64, 390-393. http://dx.doi.org/10.1099/jmm.0.000024

[37] Antonopoulou, S., Aoun, M., Alexopoulos, E.C., Baka, S., Logothetis, E. and Kalambokas, T. (2009) Fenticonazole Activity Measured by the Methods of the European Committee on Antimicrobial Susceptibility Testing and CLSI against 260 Candida Vulvovaginitis Isolates from Two European Regions and Annotations on the Prevalent Genotypes. Antimicrobial Agents and Chemotherapy, 53, 2181-2184. http://dx.doi.org/10.1128/AAC.01413-08

[38] Zhou, X., Westman, R., Hickey, R., Hansmann, M.A., Kennedy, C., Osborn, T.W. and Forney, L.J. (2009) Vaginal Microbiota of Women with Frequent Vulvovaginal Candidiasis. Infection and Immunity, 77, 4130-4135. http://dx.doi.org/10.1128/IAI.00436-09

[39] Ou, T.Y., Chang, F.M., Cheng, W.N., Lara, A., Chou, M.L., Lee, W.F., et al. (2016) Fluconazole Induces Rapid High-Frequency MTL Homozygosis with Microbiological Polymorphism in Candida albicans. Journal of Microbiology, Immunology and Infection, in Press. http://dx.doi.org/10.1016/j.jmii.2015.12.009

[40] Torres-Rodriguez, J.M., Madrenys, N., Jimenez, T. and Saballs, P. (2007) Minimal Inhibitory Concentrations of Candida Species to Five Antifungals by Using the Reference Dilution Micro Method and the E-Test. Revista Iberoamericana de Micología, 14, 115-118.

[41] Diekema, D.J., Messer, S.A., Boyken, L.B., Hollis, R.J., Kroeger, J., Tendolkar, S., et al. (2009) In Vitro Activity of Seven Systemically Active Antifungal Agents against a Large Global Collection of Rare Candida Species as Determined by CLSI Broth Microdilution Methods. Journal of Clinical Microbiology, 47, 3170-3177. http://dx.doi.org/10.1128/JCM.00942-09

[42] Spampinato, C. and Leonardi, D. (2013) Candida Infections, Causes, Targets, and Resistance Mechanisms: Traditional and Alternative Antifungal Agents. BioMed Research International, 2013, Article ID: 204237. http://dx.doi.org/10.1155/2013/204237 
Submit or recommend next manuscript to SCIRP and we will provide best service for you:

Accepting pre-submission inquiries through Email, Facebook, LinkedIn, Twitter, etc. A wide selection of journals (inclusive of 9 subjects, more than 200 journals)

Providing 24-hour high-quality service

User-friendly online submission system

Fair and swift peer-review system

Efficient typesetting and proofreading procedure

Display of the result of downloads and visits, as well as the number of cited articles

Maximum dissemination of your research work

Submit your manuscript at: http://papersubmission.scirp.org/

Or contact ojog@scirp.org 